\title{
Crizotinib changes the metabolic pattern and inhibits ATP production in A549 non-small cell lung cancer cells
}

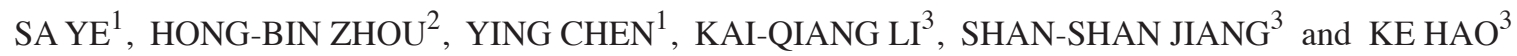 \\ Departments of ${ }^{1}$ Nutrition and ${ }^{2}$ Respiratory Medicine; ${ }^{3}$ Research Center of Blood Transfusion Medicine, \\ Ministry of Education Key Laboratory of Laboratory Medicine, Department of Blood Transfusion, Zhejiang Provincial \\ People's Hospital, People's Hospital of Hangzhou Medical College, Hangzhou, Zhejiang 310014, P.R. China
}

Received March 30, 2020; Accepted October 20, 2020

DOI: $10.3892 / \mathrm{ol} .2020 .12323$

\begin{abstract}
Crizotinib, an inhibitor of the hepatocyte growth factor receptor oncogene, has been studied extensively regarding its antitumor and clinically beneficial effects in non-small cell lung cancer (NSCLC). However, crizotinib's effects on cancer cell energy metabolism, which is linked with tumor proliferation and migration, in NSCLC are unclear. Therefore, the present study focused on crizotinib's effect on NSCLC glucose metabolism. Crizotinib's effects on glucose metabolism, proliferation, migration and apoptosis in A549 cells were explored. Several other inhibitors, including 2-DG, rotenone and MG132, were used to define the mechanism of action in further detail. Data showed that crizotinib treatment reduced A549 cell viability, increased glucose consumption and lactate production, while decreased mitochondrial transmembrane potential $(\Delta \psi \mathrm{m})$ and ATP production. Crizotinib treatment, combined with rotenone and MG132 treatment, further inhibited ATP production and $\Delta \psi \mathrm{m}$ and increased reactive oxygen species content. However, crizotinib did not suppress cell proliferation, migration, ATP production, $\Delta \psi \mathrm{m}$ or mitochondrial-related apoptosis signals further following 2-DG-mediated inhibition of glycolysis. These results indicated that crizotinib induced low mitochondrial function and compensatory high anaerobic metabolism, but failed to maintain sufficient ATP levels. The alternation of metabolic pattern and insufficient ATP supply may serve important roles in the metabolic antitumor mechanism of crizotinib in A549 cells.
\end{abstract}

Correspondence to: Dr Ke Hao, Research Center of Blood Transfusion Medicine, Ministry of Education Key Laboratory of Laboratory Medicine, Department of Blood Transfusion, Zhejiang Provincial People's Hospital, People's Hospital of Hangzhou Medical College, 158 Shangtang Road, Hangzhou, Zhejiang 310014, P.R. China

E-mail: haoke@hmc.edu.cn

Abbreviations: NSCLC, non-small cell lung cancer; $\Delta \psi \mathrm{m}$, mitochondrial transmembrane potential

Key words: crizotinib, ATP production, glycolysis, proliferation, migration

\section{Introduction}

Lung cancer is the most common cancer worldwide (1). In China in 2015, statistics showed that the lung cancer had the highest rates of morbidity ( 0.73 million new lung cancer cases) and mortality (0.6 million lung cancer deaths) (2). In total, $\sim 85 \%$ of lung cancer cases are non-small cell lung cancer (NSCLC). Crizotinib, an inhibitor targeting the oncogenes hepatocyte growth factor receptor (c-MET), ALK and ROS1, was approved in 2011 for use due to its antitumor effects in patients with NSCLC displaying abnormal c-MET pathway activation (3). c-MET is a hepatocyte growth factor receptor-induced tyrosine kinase that, when aberrantly activated or amplified, activates various signaling transduction cascades (for example the PI3K/Akt/MAPK signaling pathways), promotes tumorigenesis, metastasis, and drug resistance and leads to poor prognosis $(4,5)$.

Cellular metabolism is known to serve an important role in tumor proliferation and migration. In the early 1960s, Warburg showed that cancer cells are more likely to switch their energy source from mitochondrial oxidative phosphorylation (in normal cells) to glycolysis, and this switch has been named the 'Warburg effect' (6). Glycolysis is inefficient in generating ATP but produces more intermediates that promote tumor survival (7). Metabolic alteration cells contribute to metastasis of some tumor types $(8,9)$, for example migratory/invasive breast cancer cells specifically favor mitochondrial respiration, leading to higher ATP levels compared with those found in the primary tumor and circulating cells $(10,11)$.

Crizotinib has been studied extensively regarding its antiproliferative, antimetastatic and clinically beneficial effects in lung cancer $(12,13)$. However, more research is needed to determine whether c-MET inhibition alters energy production in NSCLC. Liu et al (14) reported that c-Met induces cytochrome c release from mitochondria, blocks c-Met-augmented loss of mitochondrial transmembrane potential $(\Delta \psi \mathrm{m})$ and inhibits apoptosis (14). A previous study showed that, in HepG2 cells, crizotinib does not affect mitochondrial respiration and has a minimal effect on glycolysis (15). These conflicting findings highlight the need to clarify the link between crizotinib and metabolism in NSCLC.

The present study aimed to explore the role of altered metabolic pattern following crizotinib treatment in A549 cells. 
To achieve this, the effects of crizotinib combined with several metabolic inhibitors on energy production, $\Delta \psi \mathrm{m}$, reactive oxygen species (ROS), proliferation and migration in NSCLC were analyzed. The level of apoptosis and autophagy were also analyzed. These experiments aimed to assess the relationship between crizotinib-induced metabolic change and the cancer cell death.

\section{Materials and methods}

Reagents. Crizotinib, rotenone and MG132 (Beyotime Institute of Biotechnology) were dissolved in DMSO and stored at $-80^{\circ} \mathrm{C}$. Before use, these reagents were diluted with RPMI-1640 culture media, so that the final DMSO concentration was $<0.1 \%$. 2-DG (Beyotime Institute of Biotechnology) was dissolved in pure water, and diluted with culture media $>100: 1$ before use. Light chain 3 I/II (LC3 I/II, cat. no. ab128025), and GAPDH (cat. no. ab9485) antibodies were purchased from Abcam, phosphorylated c-MET (p-c-MET; cat. no. 8198), c-MET (cat. no. 3077) and BAX (cat. no. 2772), BCL2 (cat. no. 4223), poly ADP-ribose polymerase (PARP; cat. no. 9542) and tubulin (cat. no. 2146) antibodies were purchased from Cell Signaling Technology, Inc.

Cell culture. The Clinical Research Center of Zhejiang Provincial People's Hospital provided A549 cells which original purchased from The Cell Bank of Type Culture Collection of the Chinese Academy of Sciences. Cells were cultured in RPMI-1640 medium supplemented with $10 \%$ fetal bovine serum (FBS; Hyclone) and $1 \%$ penicillin-streptomycin solution (Hyclone; Cyvita), and incubated at $37^{\circ} \mathrm{C}$ with $5 \% \mathrm{CO}_{2}$. Cells were seeded at 50,000 cells/well in 24-well or 6-well plates and cultured until $80-85 \%$ confluent before experimental use.

Cell viability. After cells were treated with $0-100 \mu \mathrm{M}$ crizotinib or other inhibitors, including $10 \mathrm{nM}$ rotenone, $10 \mathrm{mM}$ 2-DG or $10 \mathrm{nM} \mathrm{MG132} \mathrm{for} \mathrm{24} \mathrm{h,} 10 \mu \mathrm{l}$ MTS solution (Promega Corporation) was added to the supernatant. After $1 \mathrm{~h}$ of culture, an equivalent volume of supernatant was transferred to 96-well plates to determine the absorbance at $490 \mathrm{~nm}$ using an Absorbance Plate Reader (BioTek Instruments, Inc.).

Metabolism analysis. After cells were treated for $24 \mathrm{~h}$, $100 \mu 1$ culture supernatant was collected to determine the residual glucose concentration using a glucose assay kit (Sigma-Aldrich; Merck KGaA) and absorbance at $540 \mathrm{~nm}$. Cells were washed with PBS, and $200 \mu 1$ ATP lysate was added to the collected homogenates for analysis as previously described (16). Cellular levels of ATP was determined by using an ATP Luminometric Assay kit (Beyotime Institute of Biotechnology), lactate was tested by Lactic Acid assay kit (Nanjing Jiancheng Bioengineering Institute), and total protein was determined using the BCA Protein Assay kit (Beyotime Institute of Biotechnology).

Mitochondrial membrane potential. After $24 \mathrm{~h}$ treatment with $1 \mu \mathrm{M}$ crizotinib or other inhibitors as aforementioned, cells were loaded with mitochondrial membrane potential dye JC-1 (Beyotime Institute of Biotechnology) for $20 \mathrm{~min}$ at $37^{\circ} \mathrm{C}$. Cells were digested with trypsin and washed with PBS in preparation for BD FACSCanto II flow cytometry (BD Biosciences) according to manufacturer instructions. Red fluorescence signified high mitochondrial membrane potential, and green fluorescence presented low mitochondrial membrane potential. Data were analyzed by using FlowJo software (version 10; FlowJo, LLC).

ROS analysis. After $24 \mathrm{~h}$ treatment with $1 \mu \mathrm{M}$ crizotinib or the indicated inhibitors, cells were loaded with $2 \mathrm{mM}$ ROS fluorescence dye 2',7'-dichlorodihydrofluorescein diacetate (Beyotime Institute of Biotechnology) for $15 \mathrm{~min}$ at $37^{\circ} \mathrm{C}$. Then cells were digested with trypsin and resuspended with PBS for flow cytometry analysis as aforementioned.

Cell proliferation. The ratio of cell proliferation was analyzed following EdU incubation (Beyotime Institute of Biotechnology). Briefly, after treatment with $1 \mu \mathrm{M}$ crizotinib and various inhibitors, $10 \mu \mathrm{M}$ EdU solution was added to culture media and incubated at $37^{\circ} \mathrm{C}$ with $5 \% \mathrm{CO}_{2}$ for $2 \mathrm{~h}$, then the cells were fixed with $4 \%$ paraformaldehyde for $15 \mathrm{~min}$ and permeabilized with $0.3 \%$ Triton X-100 for $15 \mathrm{~min}$, both at room temperature. After washed with PBS, the cells were stained by Click Additive Solution and subjected to nuclear staining with Hoechst. Images were captured using an inverted Nikon Eclipse Ti fluorescence microscope (Nikon Corporation). After digested, suspended cells were used for flow cytometer analysis as aforementioned and the EdU-positive cell ratio was analyzed by using FlowJo software.

Cell migration. Cell migration assays were performed on 24-well plates with Transwell inserts (BD Biosciences). In total, $2 \times 10^{4}$ cells were seeded into the upper chamber of the Transwell plates without FBS in the RPMI-1640 culture media, while lower chambers were RPMI-1640 with $10 \%$ FBS. In total, $1 \mu \mathrm{M}$ crizotinib and inhibitors were added to the media in both chambers. After incubation for $18 \mathrm{~h}$ at $37^{\circ} \mathrm{C}$ with $5 \% \mathrm{CO}_{2}$, cells in the upper chamber were removed with a swab, while cells in the lower chamber were fixed with $4 \%$ paraformaldehyde for $15 \mathrm{~min}$ at room temperature, stained with crystal violet for $5 \mathrm{~min}$ at room temperature, and manually counted in at least five random fields under an inverted Nikon Eclipse Ti microscope.

Wound healing assay. A scratch wound assay was used to evaluate cell migration. The cell monolayer was scratched with a $10-\mu 1$ pipette tip, and then washed three times with PBS. Afterwards cells were treated for $18 \mathrm{~h}$ with $1 \mu \mathrm{M}$ crizotinib and other inhibitors in serum-free culture media. The images of scratch line were captured at two fixed positions at the beginning and the end of the experiment by Nikon light microscope at 100x magnification. These images were analyzed by Adobe Photoshop (version CS6; Adobe) and the wound recovery was calculated according to the reduction of wound area.

Western blotting. A549 cells were homogenized using RIPA lysis buffer (Beyotime Institute of Biotechnology) after exposure to $1 \mu \mathrm{M}$ crizotinib and the aforementioned inhibitors. Total protein of the cell lysates were determined by using BCA Protein Assay kit as aforementioned and then cell lysates were 
A

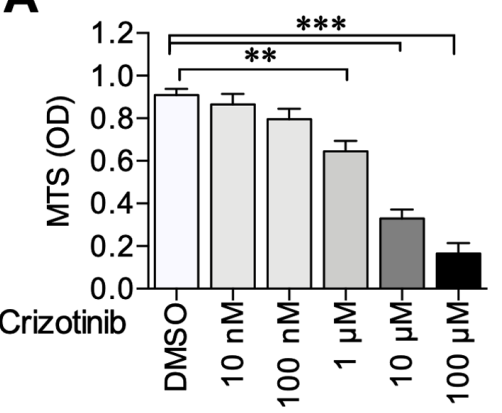

B

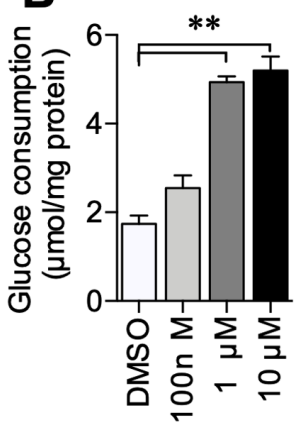

C

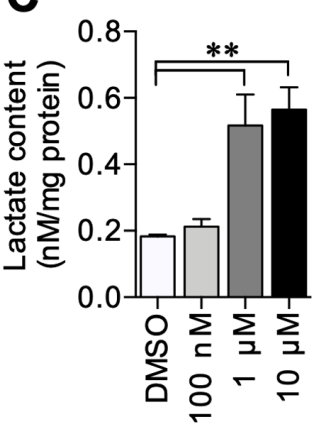

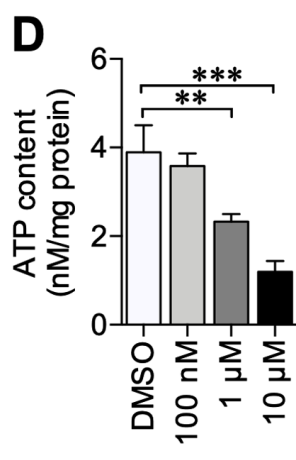

Figure 1. Crizotinib decreases A549 cell viability and glucose metabolism. (A) Viability of A549 cells after 24 h treatment with various concentrations of crizotinib. Treatment with 1-10 $\mu \mathrm{M}$ crizotinib (B) increased glucose consumption and (C) lactate content and (D) decreased ATP content of A549 cells. ${ }^{* *} \mathrm{P}<0.01,{ }^{* * *} \mathrm{P}<0.001$ vs. DMSO control group.

boiled for $15 \mathrm{~min}$. Equivalent amount of sample (50 $\mu \mathrm{g}$ protein per lane) were loaded and separated by $10 \%$ SDS-PAGE, and then transferred to polyvinylidene difluoride membranes (EMD Millipore). The membranes were blocked with 5\% skim milk powder for $2 \mathrm{~h}$ at room temperature and then incubated with LC3 I/II, p-c-MET, c-MET, BAX, BCL2, cleaved PARP, tubulin and GAPDH antibodies (all 1:1,000) overnight at $4^{\circ} \mathrm{C}$. Then the membranes were incubated with appropriate HRP-conjugated goat anti-mouse (cat. no. HA1013) or goat anti- rabbit (cat. no. HA1012) secondary antibodies (1:5,000; Hangzhou HuaAn Biotechnology Co., Ltd.) for $1 \mathrm{~h}$ at room temperature. Proteins were visualized using the ECL detection system (Beyotime Institute of Biotechnology) and the Bio-Rad gel documentation system (Bio-Rad Laboratories, Inc.). Protein bands was analyzed by ImageJ software (version 1.49; National Institutes of Health).

Immunofluorescence. The level of LC3 was estimated by immunofluorescence to analyze autophagy. A549 cells were seeded on glass coverslips and cultured until $80 \%$ confluent. After undergoing treatment for $18 \mathrm{~h}$ with $1 \mu \mathrm{M}$ crizotinib, the cells were fixed in $4 \%$ paraformaldehyde for $15 \mathrm{~min}$ at room temperature and incubated with anti-LC3 I/II antibody (1:200) at $4^{\circ} \mathrm{C}$ overnight. Then cells were incubated with 1:1,000 Alexa 488-conjugated antibody (cat. no. 4412; Cell Signaling Technology) for $1 \mathrm{~h}$ at room temperature, after that DAPI staining solution (Beyotime Institute of Biotechnology) was added to cells for $5 \mathrm{~min}$ at room temperature to indicate nuclear fluorescence. Fluorescence microscopy images were captured at x400 magnification.

Statistical analysis. All experiments were repeated at least three times and presented as mean \pm SD (unless otherwise shown) and were analyzed using one-way ANOVA followed by Tukey's post hoc test, or Student's unpaired two-tailed t-test between two groups. GraphPad Prism 6 software (GraphPad Software) was used for all analyses. $\mathrm{P}<0.05$ was considered to indicate a statistically significant difference.

\section{Results}

Crizotinib inhibits NSCLC cell viability and ATP production. A549 cells were treated with $0-100 \mu \mathrm{M}$ crizotinib to evaluate crizotinib's effect on A549 cell viability and metabolism. The results demonstrated that $1-100 \mu \mathrm{M}$ crizotinib significantly inhibited A549 cell viability compared with untreated cells (Fig. 1A). Further experiments demonstrated that 1 and $10 \mu \mathrm{M}$ crizotinib treatment induced increased glucose consumption $(\mathrm{P}<0.01)$ and lactate production $(\mathrm{P}<0.01)$ compared with the DMSO control (Fig. 1B and C); however, ATP content decreased $(\mathrm{P}<0.001)$ (Fig. 1D). The experiments aforementioned were carried out on $\mathrm{H} 1650$ cell line after $1 \mu \mathrm{M}$ crizotinib treatment and observed the same results of cell viability, glucose consumption, lactate and ATP production (Fig. S1). These results suggested that crizotinib inhibited NSCLC cell viability and alternated the cell metabolism.

Crizotinib does not suppress metabolism in 2-DG-treated cells. Overall, $10 \mathrm{nM}$ rotenone (mitochondrial complex I inhibitor) (17), $10 \mathrm{mM}$ 2-DG (glycolysis inhibitor) (18) or $10 \mathrm{nM}$ MG132 (proteasome inhibitor) (19) were added to A549 cells, in the presence or absence of crizotinib, to explore the mechanism by which crizotinib interrupts energy metabolism. All inhibitors rotenone, 2-DG and MG132 decreased A549 cell viability (Fig. 2A). Combined $1 \mu \mathrm{M}$ crizotinib with rotenone $(\mathrm{P}<0.05)$ or MG132 $(\mathrm{P}<0.05)$, further inhibited cell viability; however, $1 \mu \mathrm{M}$ crizotinib did not decrease cell viability in conjunction with 2-DG-treatment (Fig. 2A). Crizotinib further increased glucose consumption and lactate production in cells treated with rotenone $(\mathrm{P}<0.05$ and $\mathrm{P}<0.01)$ and MG132 (both $\mathrm{P}<0.01$ ), but not with 2-DG (Fig. $2 \mathrm{~B}$ and $\mathrm{C}$ ). ATP production was decreased in cells treated with $2-\mathrm{DG}(\mathrm{P}<0.01)$ and rotenone $(\mathrm{P}<0.05)$. Crizotinib did not further inhibit ATP production mediated by 2-DG treatment (Fig. 2D). These results indicated that crizotinib enhanced A549 cell glucose consumption and anaerobic respiration; however, still induced low ATP levels.

Metabolic inhibitors interrupt crizotinib-mediated inhibition of cell proliferation. Cell proliferation was assessed using EdU incorporation, and typical microscope images are shown in Fig. 3A. EdU-positive cell ratios were detected using flow cytometry, and the typical histograms are shown in Fig. S2. Similar to results obtained with cell viability, EdU data showed that all 2-DG, rotenone, and MG132 treatments inhibited the ratio of proliferating cells (Fig. 3B). Crizotinib further decreased the proliferation ratio in rotenone $(\mathrm{P}<0.05)$ 
A
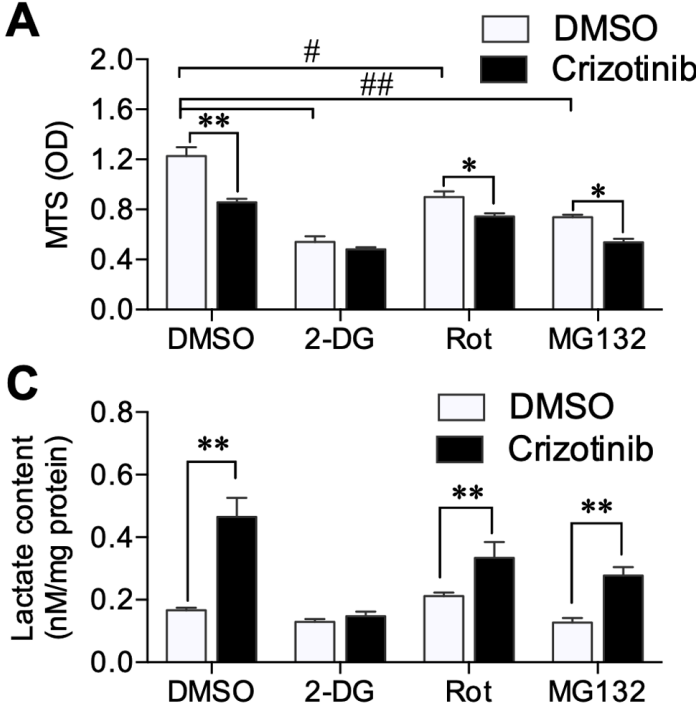

B

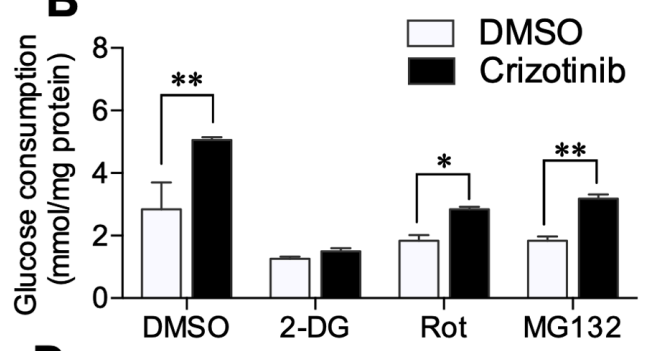

D

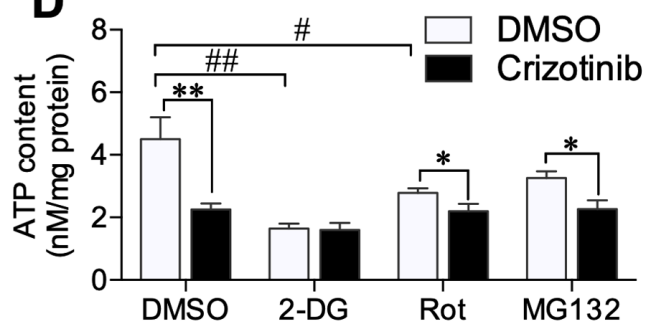

Figure 2. Effect of crizotinib treatment on A549 cell metabolism in conjunction with various inhibitors. After pretreatment with MG132, 2-DG and rotenone, the effects of $1 \mu \mathrm{M}$ crizotinib on (A) cell viability, (B) glucose consumption, (C) lactate content and (D) ATP content were determined in A549 cells. "P<0.05, ${ }^{* * *} \mathrm{P}<0.01$ vs. respective crizotinib-treated group; ${ }^{\#} \mathrm{P}<0.05,{ }^{\# \#} \mathrm{P}<0.01$ vs. DMSO control group. Rot, rotenone.

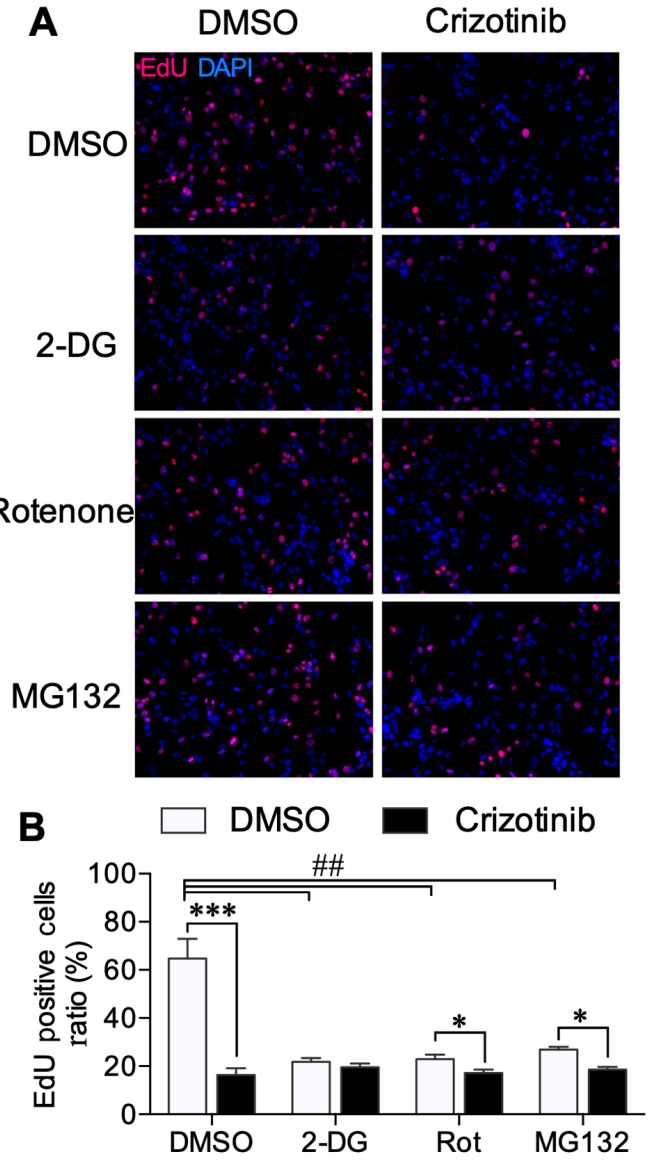

Figure 3. Effect of crizotinib on A549 cell proliferation in conjunction with various inhibitors. (A) Representative EdU images of A549 cells after treatment with crizotinib and inhibitors are shown in (magnification, $\mathrm{x} 100$ ). (B) EdU-positive cell ratio was calculated using flow cytometry. ${ }^{*} \mathrm{P}<0.05$, ${ }^{* * *} \mathrm{P}<0.001$ vs. respective crizotinib-treated group; ${ }^{\# \#} \mathrm{P}<0.01$ vs. DMSO control group. Rot, rotenone.

and MG132-treated cells $(\mathrm{P}<0.05)$, but not in 2-DG-treated cells (Fig. 3B). These results further verified the relationship between cell proliferation and crizotinib-induced metabolic alternation.

Metabolic inhibitors interrupt crizotinib-mediated inhibition of cell migration. Transwell and wound healing assays were performed to explore the effect of crizotinib on A549 cell migration. Transwell experiments demonstrated that crizotinib inhibited A549 cell migration across the membrane. 2-DG, rotenone and MG132 also decreased cell migration (Fig. 4A). When combined with rotenone $(\mathrm{P}<0.05)$ and MG132 $(\mathrm{P}<0.05)$, but not 2-DG treatment, crizotinib further suppressed A549 cell migration (Fig. 4B). The wound healing assay showed that 2-DG, rotenone and MG132 treatment did not alter the wound recovery ratio. Crizotinib treatment significantly reduced the wound recovery compared with the DMSO-treated group $(\mathrm{P}<0.01)$. For cells treated with $2-\mathrm{DG}$ in the Transwell experiment, crizotinib did not further narrow the width of the scratch wound (Fig. 5A and B). These results suggested the crizotinib-mediated inhibition of cell migration may be associated with altered metabolism.

Crizotinib decreases the $\Delta \psi m$ and increases ROS content. It was determined that crizotinib induced A549 cell $\Delta \psi \mathrm{m}$ and ROS content using flow cytometry. Crizotinib substantially decreased high $\Delta \psi \mathrm{m}$ level (JC-1 red fluorescence) compared with the DMSO-treated group $(\mathrm{P}<0.01)$ (Fig. 6A). 2-DG and rotenone decreased high $\Delta \psi \mathrm{m}$ level compared with cells only treated with DMSO, while crizotinib treatment further decreased $\Delta \psi \mathrm{m}$ in rotenone- $(\mathrm{P}<0.05)$ and MG132-treated cells $(\mathrm{P}<0.05)$ (Fig. 6B). Low $\Delta \psi \mathrm{m}$ level signal (JC-1 green fluorescence) was not significantly different between any of the groups (Fig. S3). Crizotinib induced significantly high ROS level $(\mathrm{P}<0.01)$, while 2-DG, rotenone and MG132 alone increased ROS level in A549 cells compared with the DMSO only treated group $(\mathrm{P}<0.05)$ (Fig. 6C). Only in 2-DG-treated cells did crizotinib not further increase ROS content (Fig. 6D). These results showed that crizotinib 


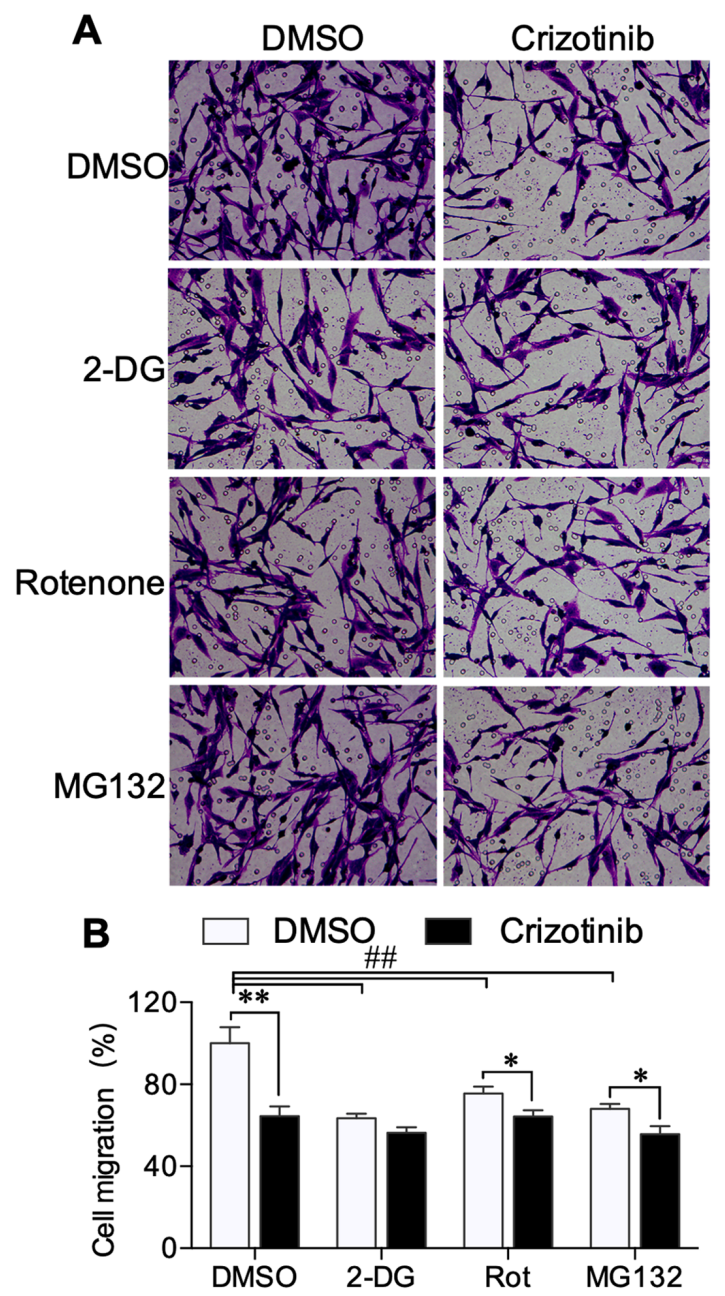

Figure 4. Effect of crizotinib on A549 cell migration in conjunction with various inhibitors in Transwell assays. (A) Representative images of A549 cell migration after treatment with crizotinib and inhibitors are shown in (magnification, x100). (B) Cell migration ratios. ${ }^{*} \mathrm{P}<0.05,{ }^{* *} \mathrm{P}<0.01$ vs. respective crizotinib-treated group; ${ }^{\# \#} \mathrm{P}<0.01$ vs. DMSO control group. Rot, rotenone.

inhibited mitochondrial respiration and increased ROS, and these crizotinib effects were limited by 2-DG-mediated inhibition of glycolysis.

Crizotinib treatment induces mitochondrial-related apoptosis. It was determined that crizotinib and inhibitors induced apoptosis using western blotting. Crizotinib increased $\mathrm{BAX}(\mathrm{P}<0.01)$ and inhibited $\mathrm{BCL}-2$ protein expression $(\mathrm{P}<0.01)$ (Fig. 7A). All inhibitors (2-DG, rotenone and MG132) alone did not change the protein levels of BAX or BCL-2. However, treatment with 2-DG did not affect crizotinib-induced BAX and BCL-2 alternations (Fig. 7B). Crizotinib enhanced cleaved PARP protein level, which is an indispensable signal in apoptosis cascade reaction (20), while the inhibitors did not change the crizotinib-induced cleaved PARP level (Fig. 7A). LC3 I/II protein levels were also evaluated using western blot and immunofluorescence to determine whether crizotinib induced autophagy. In A549 cells, $1 \mu \mathrm{M}$ crizotinib decreased p-c-MET levels (Fig. 6C). Crizotinib neither increased LC3 I/II protein levels (Fig. 7C), nor induced autolysosome aggregation (Fig. 7D). These results suggested that crizotinib activated the
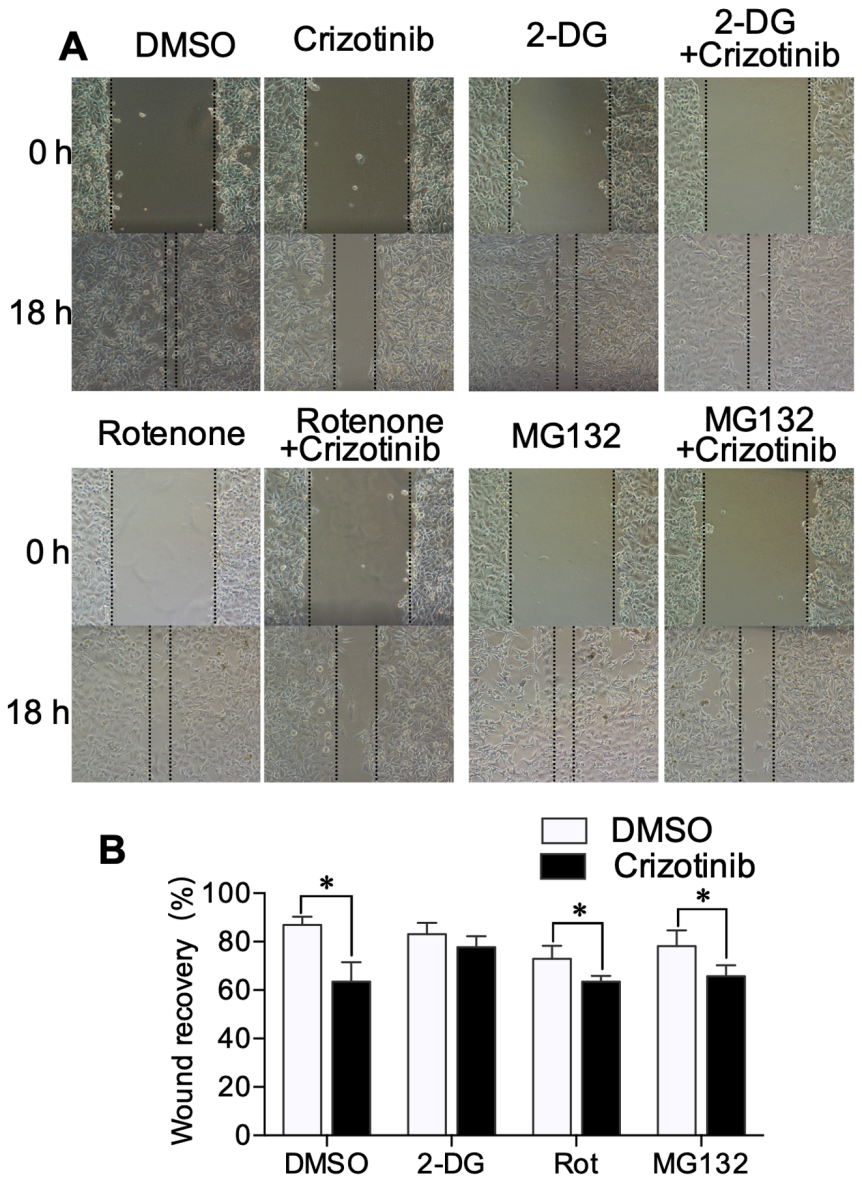

Figure 5. Effect of crizotinib on A549 cell migration in conjunction with various inhibitors in the wound healing assay. (A) Representative images of A549 cell scratches before $(0 \mathrm{~h})$ and after $(18 \mathrm{~h})$ treatment with crizotinib and inhibitors are shown in (magnification, x40). Dotted lines show the original edges immediately after scratch. (B) Wound recovery percentage was calculated in. ${ }^{*} \mathrm{P}<0.05$ vs. respective DMSO control group. Rot, rotenone.

mitochondrial pathway of apoptosis, which is associated with crizotinib-induced changes in metabolic pattern.

\section{Discussion}

In the present study, crizotinib treatment inhibited A549 cell proliferation, migration, ATP production and $\Delta \psi \mathrm{m}$, while crizotinib induced high glucose consumption, lactate and ROS content and activated mitochondrial-related apoptosis signals. However crizotinib treatment did not further suppress proliferation and migration ability after 2-DG-mediated inhibition of glycolysis. These data indicated that crizotinib inhibits mitochondrial respiration and, to compensate, enhances anaerobic respiration, but still failed to maintain sufficient ATP content. Crizotinib-induced insufficient ATP supply may play an important role in its antitumor effects.

Energy production is important for all cancer cell activity (9). Glucose metabolism produces a supply of the energy source ATP and numerous intermediaries necessary for cell proliferation and migration. Cancer cells usually display altered metabolic pattern to survive. Enhanced glycolysis or anaerobic respiration in cancer cells metabolizes more glucose compared with normal cells, which mainly 

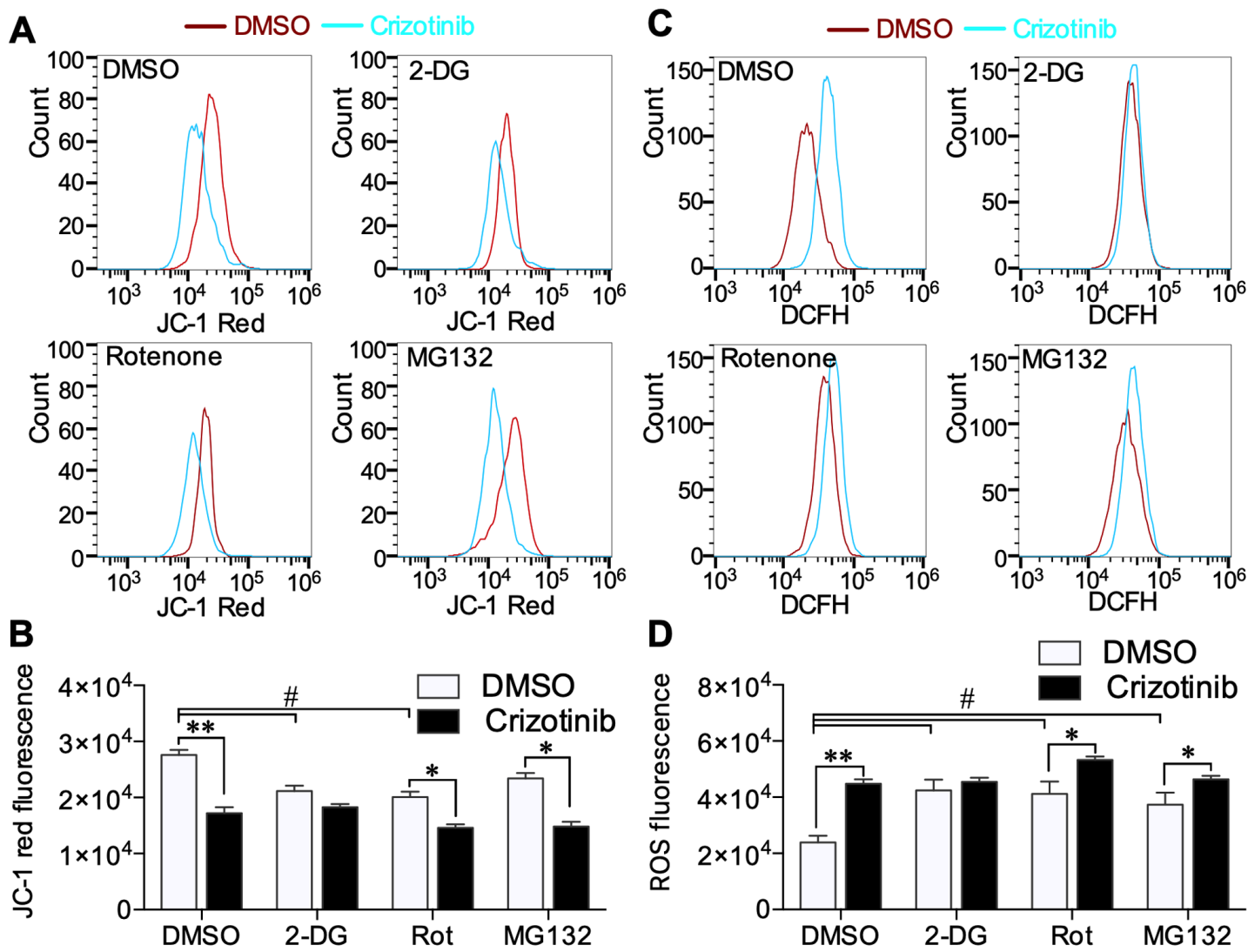

Figure 6. Effect of crizotinib on A549 cell mitochondrial membrane potential and ROS level. (A) Representative flow cytometer of JC-1 red fluorescence after $1 \mu \mathrm{M}$ crizotinib and inhibitors treatment. (B) Mean of JC-1 red fluorescence in every group. (C) DCFH fluorescence represent ROS level and (D) means of ROS fluorescence. ${ }^{*} \mathrm{P}<0.05,{ }^{* *} \mathrm{P}<0.01$ vs. respective crizotinib-treated group; ${ }^{*} \mathrm{P}<0.05$ vs. DMSO control group. Rot, rotenone; ROS, reactive oxygen species; DCFH, 2',7'-dichlorodihydrofluorescein diacetate.

depended on aerobic respiration (21), and accumulating lactate produces an acidic microenvironment $(7,22)$. Thus, therapeutic targeting of glycolysis is an important and effective antitumor strategy $(23,24)$. However, a growing number of studies have shown that some cancer cells do not show enhanced glycolysis, but rather still rely on oxidative phosphorylation $(25,26)$. Previously, the complexity of metabolic reprogramming was demonstrated by differences in glucose metabolism in primary, circulating and metastatic tumor cells $(9,10)$.

It was reported that inhibition of c-MET enhances oridonin-mediated reduction of $\Delta \psi \mathrm{m}$, resulting in the apoptosis of A549 cells (14). Therefore, it was hypothesized that crizotinib might also alter metabolism in NSCLC cells. In the present study, 1-100 $\mu \mathrm{M}$ crizotinib was shown to inhibit A549 cell viability, and $1 \mu \mathrm{M}$ crizotinib was shown to inhibit ATP production and reduce $\Delta \psi \mathrm{m}$; however, this treatment also stimulated glucose consumption and lactate production. A previous study suggested that there is a close link between attenuated mitochondrial bioenergetic function and enhanced glycolysis in A549 cells (27). The current results indicated that crizotinib suppressed mitochondrial oxidative phosphorylation and may compensate via enhanced glycolysis and anaerobic respiration in A549 cells. However, this compensation still failed to maintain ATP levels. It was also observed this phenomenon in another NSCLC cell line, H1650 cells, which showed similar results after treatment with $1 \mu \mathrm{M}$ crizotinib (Fig. S1). However, in head and neck squamous cell carcinoma, crizotinib caused a notable decrease in glycolytic capacity and inhibited lactate production (28). In hepatic cancer HepG2 cells, crizotinib did not affect mitochondrial oxidation and only weakly affected glycolysis (15). These findings suggest the crizotinib may exert different effects in different types of cancer depending on different metabolic pattern. The primary lung cancer A549 cell line depends partly on mitochondrial oxidative phosphorylation for ATP production $(29,30)$ and A549 cells consume much more oxygen compared with metastatic tumor cells, such as H1299 and H460 (31).

Additional experiments aimed to explore the details of crizotinib treatment on cell metabolism. A549 cells were pretreated with 2-DG, rotenone and MG132 to block specific pathways. 2-DG competes with glucose and can be transported into cells, but cannot be used as a substrate in glycolysis (18). It has been reported that 2-DG decreases the migration of triple-negative breast cancer cells, supporting a link between metabolic dysfunction and decreased migration (32). A previous study demonstrated that 2-DG attenuates ATP production, and also inhibits mitochondrial bioenergetics (33). 2-DG combined with other antitumor drugs, such as metformin, propranolol or docetaxel, effectively prevents cell proliferation and induces apoptosis in prostate cancer cells and other solid tumors, for example NSCLC and adenoid-cystic carcinoma $(34,35)$. The present study observed that 2-DG inhibited ATP production, proliferation and migration of A549 cells. However, crizotinib 

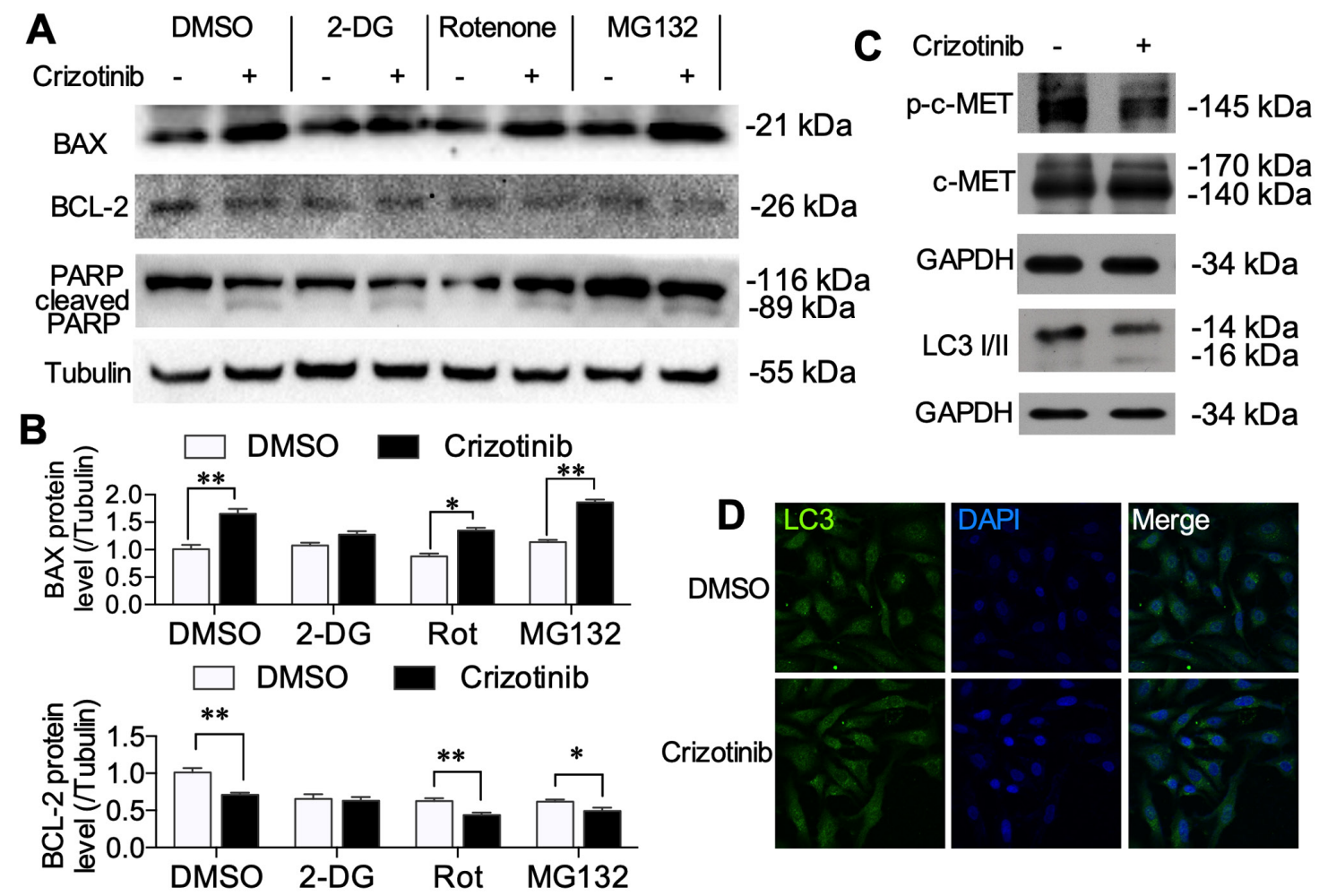

Figure 7. Effect of crizotinib on A549 cell apoptosis and autophagy. (A) Expression level of BAX, BCL-2 and PARP after crizotinib and inhibitors treatment were detected using western blotting. (B) Gray levels of BAX and BCL-2. (C) Effect of $1 \mu \mathrm{M}$ crizotinib treatment on p-MET and LC3 I/II protein levels in A549 cells determined using western blotting. (D) Representative LC3 immunofluorescence in A549 cells following crizotinib treatment (magnification, $\mathrm{x} 400) .{ }^{*} \mathrm{P}<0.05,{ }^{* *} \mathrm{P}<0.01$ vs. respective crizotinib-treated group. Rot, rotenone; PARP, poly ADP-ribose polymerase; p-MET, phosphorylated hepatocyte growth factor receptor.

in 2-DG-pretreated cells did not further inhibit ATP production, $\Delta \psi \mathrm{m}$ or ROS level. These data indicated that crizotinib enhanced cell glycolysis, which can be blocked by 2-DG pretreatment, and consequently induced notably lower glucose consumption and ATP production. These results demonstrated that different metabolic patterns in cancer cells may cause variable responses to crizotinib therapy.

Rotenone is a specific inhibitor of the mitochondrial respiratory chain complex I (17). Rotenone decreases breast cancer cells, pancreatic cancer cells and lung cancer cell survival in low glucose conditions in vitro (17). The present study showed that rotenone alone notably suppressed ATP production, $\Delta \psi \mathrm{m}$ and cell proliferation. Combined with rotenone, treatment with crizotinib further decreased cell proliferation and migration, which suggested that crizotinib affects not only mitochondrial oxidation but also other signaling pathways.

Low $\Delta \psi \mathrm{m}$ induces cytochrome c release from the mitochondria and also initiates apoptosis (36). The BCL family of proteins serve a role in regulation of mitochondrial membrane permeability and the mitochondrial apoptotic pathway (37). The present study determined the pro-apoptotic BAX and antiapoptotic BCL-2 protein levels (37). The results showed that crizotinib induced high BAX and low BCL-2 protein expression, while in 2-DG-pretreated cells, crizotinib did not further change the BAX and BCL-2 protein levels, which was consistent with the results in the metabolism and $\Delta \psi \mathrm{m}$ experiments. It has been reported that crizotinib induces apoptosis in H2228 lung cancer cells (38). The present study detected cleaved PARP to analyze A549 cell apoptosis. The data showed that crizotinib induced high cleaved PARP levels in A549 cells with or without metabolic inhibitors, which suggested that crizotinib induced apoptosis.

Reportedly, 4-8 $\mu \mathrm{M}$ crizotinib treatment induces autophagy in lung cancer cell lines, including SPC-A1 and H827 (39). There is evidence that autophagy-induced protein degeneration can fuel cellular metabolism, and autophagy inhibition impairs the proliferation of tumor cells (40). However, in the present study, LC3 I/II protein was not significantly increased or aggregated following treatment with $1 \mu \mathrm{M}$ crizotinib. It was also demonstrated that the ubiquitin-proteasome inhibitor MG132 was ineffective in blocking the effect of crizotinib on ATP production, cell proliferation and migration. These findings indicated that low concentrations of crizotinib may not interrupt protein degradation via autophagy or the ubiquitin-proteasome pathway. The present study indicated that the alternation of metabolic pattern serves important roles in the antitumor effect of crizotinib, which may contribute to different therapy outcomes in a clinical setting. However, in the present study, the molecular mechanisms underpinning crizotinib-induced metabolic alternation were not resolved, therefore in the future more molecular experiments are needed to investigate these.

In conclusion, the present study reported that crizotinib treatment inhibited proliferation, migration and cellular ATP production and induced mitochondrial apoptosis in A549 cells. Further experiments with metabolic inhibitors clarified that crizotinib shifted metabolic pattern and suppressed ATP supply, leading to low mitochondrial function and 
compensatory high anaerobic respiration. These alternations of metabolic pattern and insufficient ATP supply may play important roles in anti-tumor effect of crizotinib.

\section{Acknowledgements}

Not applicable.

\section{Funding}

The present study was supported by grants from The National Natural Science Foundation of China (grant no. 81600595), The Natural Science Foundation of Zhejiang Province (grant nos. LY17H160063, LQ16H070003 and LQ17H160017) and The Medicine and Health Research Foundation of Zhejiang Province (grant nos. 2017KY196 and 2020KY012).

\section{Availability of data and materials}

The datasets used and/or analyzed during the current study are available from the corresponding author on reasonable request.

\section{Authors' contributors}

SY and KH designed this study. SY, HZ, YC and KL performed the experiments. SY, SJ and HK performed data analyses. SY and HK wrote the manuscript. All authors read and approved the final manuscript.

\section{Ethics approval and consent to participate}

Not applicable.

\section{Patient consent for publication}

Not applicable.

\section{Competing interests}

The authors declare that they have no competing interests.

\section{References}

1. Puxty K, Grant CH, McLoone P, Sloan B, Quasim T, Hulse K and Morrison DS: Factors associated with intensive care admission in patients with lung cancer: A population-based observational study of 26,731 patients. BMC Pulm Med 20: 36, 2020.

2. Chen W, Zheng R, Baade PD, Zhang S, Zeng H, Bray F, Jemal A, Yu XQ and He J: Cancer statistics in China, 2015. CA Cancer J Clin 66: 115-132, 2016.

3. Watermann I, Schmitt B, Stellmacher F, Müller J, Gaber R, Kugler C, Reinmuth N, Huber RM, Thomas M, Zabel P, et al: Improved diagnostics targeting c-MET in non-small cell lung cancer: Expression, amplification and activation? Diagn Pathol 10: 130, 2015.

4. Szturz P, Raymond E, Abitbol C, Albert S, de Gramont A and Faivre S: Understanding c-MET signalling in squamous cell carcinoma of the head \& neck. Crit Rev Oncol Hematol 111: 39-51, 2017.

5. Moro-Sibilot D, Cozic N, Pérol M, Mazières J, Otto J, Souquet PJ, Bahleda R, Wislez M, Zalcman G, De Guibert S, et al: Crizotinib in c-MET- or ROS1-positive NSCLC: Results of the AcSe phase II trial. Ann Oncol 30: 1985-1991, 2019.
6. Warburg O: On respiratory impairment in cancer cells. Science 124: 269-270, 1956.

7. Zhao Y, Butler EB and Tan M: Targeting cellular metabolism to improve cancer therapeutics. Cell Death Dis 4: e532, 2013.

8. Pan H, Wang BH, Li ZB, Gong XG, Qin Y, Jiang Y and Han WL: Mitochondrial superoxide anions induced by exogenous oxidative stress determine tumor cell fate: An individual cell-based study. J Zhejiang Univ Sci B 20: 310-321, 2019.

9. Yang D and Kim J: Mitochondrial retrograde signalling and metabolic alterations in the tumour microenvironment. Cells 8 : $275,2019$.

10. LeBleu VS, O'Connell JT, Gonzalez Herrera KN, Wikman H, Pantel K, Haigis MC, de Carvalho FM, Damascena A, Domingos Chinen LT, Rocha RM, et al: PGC-1 $\alpha$ mediates mitochondrial biogenesis and oxidative phosphorylation in cancer cells to promote metastasis. Nat Cell Biol 16: 992-1003, 1-15, 2014.

11. Dupuy F, Tabaries S, Andrzejewski S, Dong Z, Blagih J, Annis MG, Omeroglu A, Gao D, Leung S, Amir E, et al: PDK1-dependent metabolic reprogramming dictates metastatic potential in breast cancer. Cell Metab 22: 577-589, 2015.

12. Camidge DR, Kim HR, Ahn MJ, Yang JC, Han JY, Lee JS, Hochmair MJ, Li JY, Chang GC, Lee KH, et al: Brigatinib versus crizotinib in ALK-positive non-small-cell lung cancer. N Engl J Med 379: 2027-2039, 2018.

13. Wu YL, Yang JC, Kim DW, Lu S, Zhou J, Seto T, Yang JJ, Yamamoto N, Ahn MJ, Takahashi T, et al: Phase II study of crizotinib in East Asian patients with ROS1-positive advanced non-small-cell lung cancer. J Clin Oncol 36: 1405-1411, 2018.

14. Liu Y, Liu JH, Chai K, Tashiro S, Onodera S and Ikejima T: Inhibition of c-Met promoted apoptosis, autophagy and loss of the mitochondrial transmembrane potential in oridonin-induced A549 lung cancer cells. J Pharm Pharmacol 65: 1622-1642, 2013.

15. Mingard C, Paech F, Bouitbir J and Krahenbuhl S: Mechanisms of toxicity associated with six tyrosine kinase inhibitors in human hepatocyte cell lines. J Appl Toxicol 38: 418-431, 2018.

16. Hao K, Kong FP, Gao YQ, Tang JW, Chen J, Evans AM, Lightman SL, Chen XQ and Du JZ: Inactivation of corticotropin-releasing hormone-induced insulinotropic role by high-altitude hypoxia. Diabetes 64: 785-795, 2015.

17. Palorini R, Simonetto T, Cirulli $\mathrm{C}$ and Chiaradonna F: Mitochondrial complex I inhibitors and forced oxidative phosphorylation synergize in inducing cancer cell death. Int J Cell Biol 2013: 243876, 2013.

18. Zhu Z, Jiang W, McGinley JN and Thompson HJ: 2-Deoxyglucose as an energy restriction mimetic agent: Effects on mammary carcinogenesis and on mammary tumor cell growth in vitro. Cancer Res 65: 7023-7030, 2005

19. Harhouri K, Navarro C, Depetris D, Mattei MG, Nissan X, Cau P, De Sandre-Giovannoli A and Lévy N: MG132-induced progerin clearance is mediated by autophagy activation and splicing regulation. EMBO Mol Med 9: 1294-1313, 2017.

20. Liu X, Kang J, Wang H and Huang T: Mitochondrial ROS contribute to oridonin-induced HepG2 apoptosis through PARP activation. Oncol Lett 15: 2881-2888, 2018.

21. Kim JH, Nam B, Choi YJ, Kim SY, Lee JE, Sung KJ, Kim WS, Choi CM, Chang EJ, Koh JS, et al: Enhanced glycolysis supports cell survival in EGFR-mutant lung adenocarcinoma by inhibiting autophagy-mediated EGFR degradation. Cancer Res 78: 4482-4496, 2018.

22. Anemone A, Consolino L, Arena F, Capozza M and Longo DL: Imaging tumor acidosis: A survey of the available techniques for mapping in vivo tumor $\mathrm{pH}$. Cancer Metastasis Rev 38: 25-49, 2019.

23. Martinez-Outschoorn UE, Peiris-Pagés M, Pestell RG, Sotgia F and Lisanti MP: Cancer metabolism: A therapeutic perspective. Nat Rev Clin Oncol 14: 113, 2017.

24. Avagliano A, Ruocco MR, Aliotta F, Belviso I, Accurso A, Masone S, Montagnani S and Arcucci A: Mitochondrial flexibility of breast cancers: A growth advantage and a therapeutic opportunity. Cells 8: 401, 2019.

25. Weinberg F, Hamanaka R, Wheaton WW, Weinberg S, Joseph J, Lopez M, Kalyanaraman B, Mutlu GM, Budinger GR and Chandel NS: Mitochondrial metabolism and ROS generation are essential for Kras-mediated tumorigenicity. Proc Natl Acad Sci USA 107: 8788-8793, 2010

26. Vyas S, Zaganjor E and Haigis MC: Mitochondria and cancer. Cell 166: 555-566, 2016. 
27. Wu M, Neilson A, Swift AL, Moran R, Tamagnine J, Parslow D, Armistead S, Lemire K, Orrell J, Teich J, et al: Multiparameter metabolic analysis reveals a close link between attenuated mitochondrial bioenergetic function and enhanced glycolysis dependency in human tumor cells. Am J Physiol Cell Physiol 292: C125-C136, 2007.

28. Kumar D, New J, Vishwakarma V, Joshi R, Enders J, Lin F, Dasari S, Gutierrez WR, Leef G, Ponnurangam S, et al: Cancer-associated fibroblasts drive glycolysis in a targetable signaling loop implicated in head and neck squamous cell carcinoma progression. Cancer Res 78: 3769-3782, 2018.

29. Hensley CT, Faubert B, Yuan Q, Lev-Cohain N, Jin E, Kim J, Jiang L, Ko B, Skelton R, Loudat L, et al: Metabolic heterogeneity in human lung tumors. Cell 164: 681-694, 2016.

30. Faubert B, Li KY, Cai L, Hensley CT, Kim J, Zacharias LG, Yang C, Do QN, Doucette S, Burguete D, et al: Lactate metabolism in human lung tumors. Cell 171: 358-371.e9, 2017.

31. Cruz-Bermúdez A, Vicente-Blanco RJ, Laza-Briviesca R, García-Grande A, Laine-Menéndez S, Gutiérrez L, Calvo V, Romero A, Martín-Acosta P, García JM and Provencio M: PGC-1alpha levels correlate with survival in patients with stage III NSCLC and may define a new biomarker to metabolism-targeted therapy. Sci Rep 7: 16661, 2017.

32. O'Neill S, Porter RK, McNamee N, Martinez VG and O'Driscoll L: 2-Deoxy-D-Glucose inhibits aggressive triple-negative breast cancer cells by targeting glycolysis and the cancer stem cell phenotype. Sci Rep 9: 3788, 2019.

33. Maximchik $P$, Abdrakhmanov A, Inozemtseva $E$, Tyurin-Kuzmin PA, Zhivotovsky B and Gogvadze V: 2-Deoxy-D-glucose has distinct and cell line-specific effects on the survival of different cancer cells upon antitumor drug treatment. FEBS J 285: 4590-4601, 2018.
34. Raez LE, Papadopoulos K, Ricart AD, Chiorean EG, Dipaola RS, Stein MN, Rocha Lima CM, Schlesselman JJ, Tolba K, Langmuir VK, et al: A phase I dose-escalation trial of 2-deoxy-D-glucose alone or combined with docetaxel in patients with advanced solid tumors. Cancer Chemother Pharmacol 71: 523-530, 2013

35. Brohée L, Peulen O, Nusgens B, Castronovo V, Thiry M, Colige AC and Deroanne CF: Propranolol sensitizes prostate cancer cells to glucose metabolism inhibition and prevents cancer progression. Sci Rep 8: 7050, 2018.

36. Guerra-Castellano A, Díaz-Quintana A, Pérez-Mejías G, Elena-Real CA, González-Arzola K, García-Mauriño SM, De la Rosa MA and Díaz-Moreno I: Oxidative stress is tightly regulated by cytochrome $\mathrm{c}$ phosphorylation and respirasome factors in mitochondria. Proc Natl Acad Sci USA 115: 7955-7960, 2018.

37. Peña-Blanco A and García-Sáez AJ: Bax, Bak and beyond-mitochondrial performance in apoptosis. FEBS J 285: 416-431, 2018.

38. Lu H, Wu S, Chen H, Huang Y, Qiu G, Liu L and Li Y: Crizotinib induces apoptosis of lung cancer cells through JAK-STAT pathway. Oncol Lett 16: 5992-5996, 2018.

39. You L, Shou J, Deng D, Jiang L, Jing Z, Yao J, Li H, Xie J, Wang Z, Pan Q, et al: Crizotinib induces autophagy through inhibition of the STAT3 pathway in multiple lung cancer cell lines. Oncotarget 6: 40268-40282, 2015.

40. Kimmelman AC and White E: Autophagy and tumor metabolism. Cell Metab 25: 1037-1043, 2017.

(i) $(5)$ This work is licensed under a Creative Commons c. Attribution-NonCommercial-NoDerivatives 4.0 International (CC BY-NC-ND 4.0) License. 